\title{
Epilepsia Partialis Continua in Hyperosmolar Nonketotic Hyperglycemia
}

\author{
Rahul Rai ${ }^{1}$ Pawan Dhull ${ }^{2}$ Yogesh Kumar ${ }^{3}$ Shaman Gill ${ }^{\circledR 0}$ Aneesh Mohimen ${ }^{4}$ Amit S. Nachankar ${ }^{30}$
}

1 Department of Medicine, Command Hospital, Lucknow, Uttar Pradesh, India

2 Department of Neurology, Command Hospital, Lucknow, Uttar Pradesh, India

3 Department of Endocrinology, Command Hospital, Lucknow, Uttar Pradesh, India

${ }^{4}$ Department of Radiodiagnosis, Command Hospital, Lucknow, Uttar Pradesh, India

J Neurosci Rural Pract 2021;12:817-820.

Type 2 diabetes mellitus (T2DM) is often associated with hyperglycemic emergencies due to diet noncompliance, drug default, or rarely as initial presentation. Often hyperosmolar nonketotic hyperglycemia (HONK) occurs typically in elderly T2DM patient with severe dehydration and altered sensorium. Though T2DM is associated neurological complications like diabetic neuropathy, seizures occur mostly with hypoglycemia. Seizures are seen in around 25\% of T2DM patients with changes in serum sodium or changes in osmolality. Local cerebral damage, cerebral microvascular lesions, metabolic factors, and gene mutations are also some other mechanisms postulated for the development of seizure in T2DM. ${ }^{1}$

\section{Case}

Our patient was a 72-year-old man with T2DM, hypertension, and coronary artery disease (post-coronary artery bypass grafting) presented with abnormal movement of left face, left upper, and left lower limb with altered sensorium of 2 days. Clinically, he was E3V4M5 with deviation of right angle of mouth. He had random plasma sugar of $612 \mathrm{mg} / \mathrm{dL}$ with plasma osmolarity of $328 \mathrm{mOsm} / \mathrm{kg}$ without acidosis or ketosis. Urgent computed tomography scan head was normal. His treatment included intravenous fluids and electrolytes with continuous intravenous insulin in intensive care unit.

He had refractory seizures despite control of hyperglycemia and he was started on intravenous levetiracetam. Still, he continued to have intermittent focal partial seizures after

published online September 16, 2021
DOI https://doi.org/ 10.1055/s-0041-1734004. ISSN 0976-3147.
Address for correspondence Amit S. Nachankar, DNB, Department of Medicine, Command Hospital, Kariappa Marg, Lucknow, Uttar Pradesh 226002, India (e-mail: anasvini@gmail.com).

48 hours of admission requiring phenytoin. Neurologically, he had epilepsia partialis continua (EPC) and eventually required triple antiepileptics (levetiracetam, phenytoin, and clobazam) for effective seizure control. His diffusionweighted magnetic resonance imaging (MRI) brain (-Fig. 1A, B) showed unilateral cortical restricted diffusion seen in right posterior cerebral hemisphere involving the parieto-temporal-occipital lobes, most marked in medial occipital lobe with sparing of frontal lobe. There was associated T2 white matter hypointensity seen involving the subcortical white matter of the right parieto-occipital lobes (-Fig. 1C). Confluent T2/FLAIR (fluid-attenuated inversion recovery) images showed hyperintense foci in the bilateral cerebral white matter-FAZEKA Grade III.

Despite standard of care, he had focal status epilepticus with respiratory distress requiring mechanical ventilation under sedation. After prolonged ventilator support, he succumbed to ventilator-associated pneumonia.

\section{Discussion}

EPC is a very uncommon syndrome associated with recurrent somatomotor seizures usually with preserved sensorium. Intracranial structural lesions like stroke, tumor, abscess, or head trauma are the most common causes of EPC but it can also result from a metabolic disorder.

Seizure is an uncommon manifestation in HONK and very rarely it is an initial manifestation of HONK despite normal
(C) 2021. Association for Helping Neurosurgical Sick People. All rights reserved.

This is an open access article published by Thieme under the terms of the Creative Commons Attribution-NonDerivative-NonCommercial-License, permitting copying and reproduction so long as the original work is given appropriate credit. Contents may not be used for commercial purposes, or adapted, remixed, transformed or built upon. (https://creativecommons.org/ licenses/by-nc-nd/4.0/)

Thieme Medical and Scientific Publishers Pvt. Ltd., A-12, 2nd Floor, Sector 2, Noida-201301 UP, India 

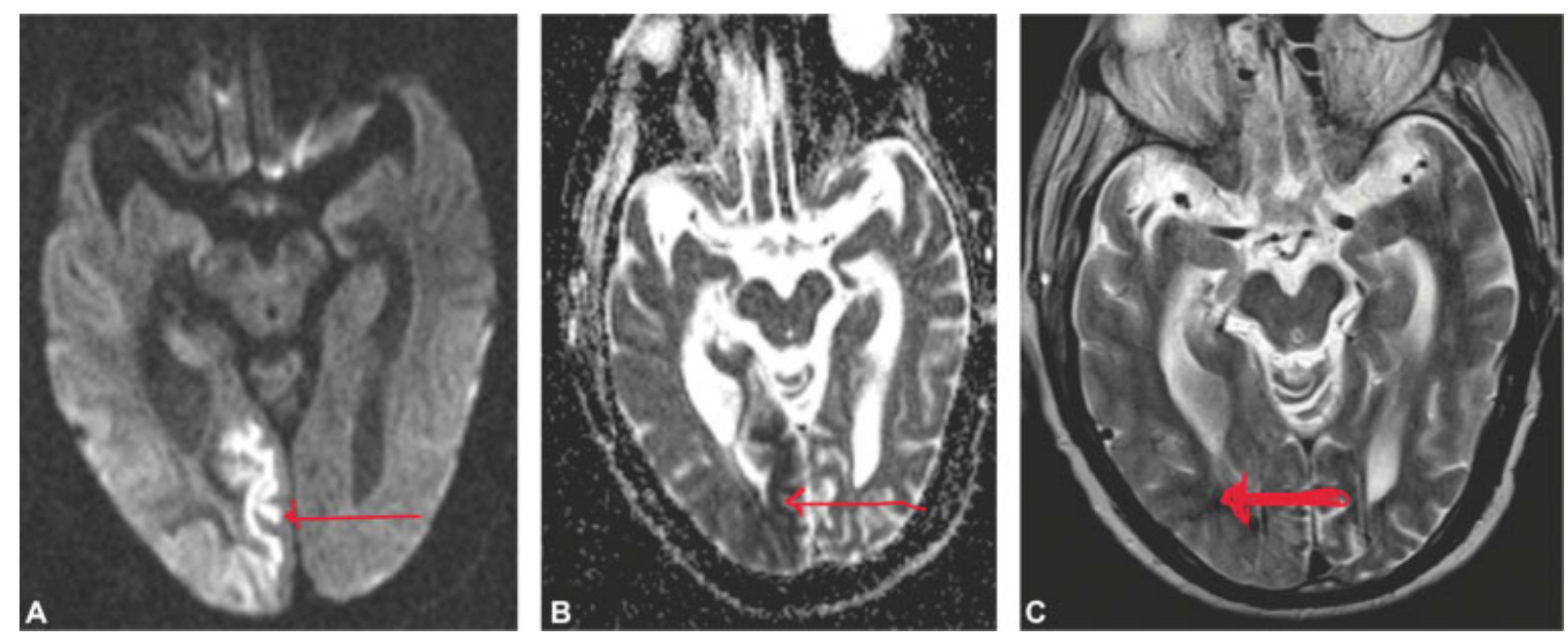

Fig. 1 Magnetic resonance imaging brain. (A) Diffusion-weighted image, (B) apparent diffusion coefficient map, and (C) T2-weighted image showing cortical diffusion restriction (thin arrows) and white matter hypointensity on T2-weighted image (thick arrow).

neuroimaging. ${ }^{2}$ Around $19 \%$ of patients with HONK with seizures have focal seizures-mainly simple motor seizures. ${ }^{3}$ Our case also demonstrated EPC with focal status epilepticus. Most common origin of focal seizure is occipital lobe, though rarely it may originate from frontal or parietal lobes. ${ }^{4}$ Seizures associated with HONK are classically resistant to antiepileptics and cease with control of hyperglycemia, but they recur if glycemic control deteriorates. ${ }^{5}$ In our case, we had EPC resistant to control of hyperglycemia but controlled with triple antiepileptics.

First description of focal seizures in HONK was done by Maccario et al in $1965 .^{2}$ Later many retrospective studies and case series described this association. ${ }^{6}$ In majority, seizures may reveal previously undiagnosed T2DM. ${ }^{7}$ Neurological deficits associated with HONK vary and motor seizures are mostly partial with postictal motor deficit. Often these begin as partial seizures with secondary generalization. ${ }^{8}$ Some other neurological manifestations in HONK include speech abnormality, unilateral loss of sensation, optic hallucinations, and field loss apart from focal seizure as EPC. ${ }^{9}$

\section{Pathogenesis of Seizures in HONK}

Seizures in HONK are due to multifactorial etiology with hyperglycemia as common underlying cause. Maccario et al suggested that serum hyperosmolality with resulting intraand extracellular fluid and electrolyte dysequilibrium (e.g., hyponatremia) is possible etiology. ${ }^{10}$ HONK state results in a hyperosmolar gradient between the intra- and extracellular neuronal environments, leading to intracellular dehydration thereby inducing seizures. ${ }^{3}$ HONK state may cause increased GABA metabolism resulting in extracellular glutamate collection and reducing epilepsy threshold. ${ }^{11}$ Disrupted blood-brain barrier is also considered as a etiology of epilepsy in HONK. ${ }^{12}$

Epilepsy is unusual with diabetic ketoacidosis as epilepsy threshold is increased by ketosis and intracellular acidosis. ${ }^{3}$ Mechanisms proposed to explain the antiseizure benefits of ketogenesis include increased resilience of neurons, inhibition of transporter on channels by ketone bodies and/or fatty acids, and increased synthesis of the inhibitory neurotransmitter GABA.

HONK also causes reversible focal ischemia by decreasing cerebral blood flow. ${ }^{13}$ The resultant hyperviscosity and reduced oxygen carrying capacity of blood lead to anaerobic state, thereby MRI features. Only certain brain regions are relatively vulnerable to hypoxic ischemia in HONK state and the axons in these areas get affected resulting in excessive free radical generation or collection of iron, leading to MRI features of T2 and FLAIR hypointensities. ${ }^{14}$

Though the hyperglycemia affects entire brain, it is not known how local brain areas only affected without affection of preexisting brain lesion. Seizure activity causes diffusion restriction with hyperintensities on T2 and FLAIR mode in the neighboring brain parenchyma. Increased energy demand during seizure in the epileptic zone is seen as vasodilation and a hypermetabolic state. An association between MRI features and epilepsy is observed in HONK. In some cases, a total reversion of the MRI features occurs demonstrating HONK-related temporary pathophysiological changes. ${ }^{15}$

\section{Conclusion}

First onset seizure in elderly with T2DM needs neuroimaging first to rule out organic brain pathology before incriminating hyperglycemia as cause of seizure. Hyperglycemia with HONK state is very rare cause of seizures in T2DM compared with hypoglycemia. Many possible mechanisms for seizure in HONK state have been described but exact mechanism is unknown. EPC is one of the seizure syndromes seen in HONK state. MRI changes in HONK states are typical and, in some cases, may have complete resolution after recovery. Though seizures due to HONK state should ideally get controlled with control of hyperglycemia, many a times single or multiple antiepileptic drugs are warranted for effective seizure control.

\section{Conflict of Interest}

None declared. 


\section{References}

1 Yun C, Xuefeng W. Association between seizures and diabetes mellitus: a comprehensive review of literature. Curr Diabetes Rev 2013;9(04):350-354

2 MacCario M, Messis CP, Vastola EF. Focal seizures as a manifestation of hyperglycemia without ketoacidosis. A report of seven cases with review of the literature. Neurology 1965;15:195-206

3 Singh BM, Strobos RJ. Epilepsia partialis continua associated with nonketotic hyperglycemia: clinical and biochemical profile of 21 patients. Ann Neurol 1980;8(02):155-160

4 Huang CW, Hsieh YJ, Pai MC, Tsai JJ, Huang CC. Nonketotic hyperglycemia-related epilepsia partialis continua with ictal unilateral parietal hyperperfusion. Epilepsia 2005;46(11):1843-1844

5 Hennis A, Corbin D, Fraser H. Focal seizures and non-ketotic hyperglycaemia. J Neurol Neurosurg Psychiatry 1992;55(03): 195-197

6 Brick JF, Gutrecht JA, Ringel RA. Reflex epilepsy and nonketotic hyperglycemia in the elderly: a specific neuroendocrine syndrome. Neurology 1989;39(03):394-399

7 Tiamkao S, Pratipanawatr T, Tiamkao S, Nitinavakarn B, Chotmongkol V, Jitpimolmard S. Seizures in nonketotic hyperglycaemia. Seizure 2003;12(06):409-410
8 Pavel I, Bonaparte H, Pirvulescu M, Covanov D. Hyperosmotic diabetic coma without acido-ketosis. Stud Cercet Med Interna 1965;40:145-155

9 Cochin JP, Hannequin D, Delangre T, Guegan-Massardier E, Augustin P. [Continuous partial epilepsy disclosing diabetes mellitus]. Rev Neurol (Paris) 1994;150(03):239-241

10 Maccario M. Neurological dysfunction associated with nonketotic hyperglycemia. Arch Neurol 1968;19(05):525-534

11 Ozer F, Mutlu A, Ozkayran T. Reflex epilepsy and non-ketotic hyperglycemia. Epileptic Disord 2003;5(03):165-168

12 Dong Wook K, Yeonsil M, Hong G, Jin Woo C, Jeeyoung O. Bloodbrain barrier disruption is involves in seizure and hemianopia in non-ketotic hyperglycaemia. Neurologist 2011;17(03):

13 Duckrow RB, Beard DC, Brennan RW. Regional cerebral blood flow decreases during hyperglycemia. Ann Neurol 1985;17(03): 267-272

14 Ida M, Mizunuma K, Hata Y, Tada S. Subcortical low intensity in early cortical ischemia. AJNR Am J Neuroradiol 1994;15(07): 1387-1393

15 Hwang KJ, Yoon S, Park KC. Non-ketotic hyperglycaemia presenting as epilepsia partialis continua. Epileptic Disord 2016;18(02): 201-203 